\title{
Model-based quantifiation of As mobility within the redox transition zones (RTZs) marking the interface of Holocene/Pleistocene aquifers
}

\author{
BHASKER RATHI $^{1 *}$, ILKA WALLIS ${ }^{2}$, JING SUN $^{3}$, JAMES $^{2}$ \\ JAMIESON $^{45}$, OLAF A. CIRPKA ${ }^{1}$, AND HENNING \\ PROMMER $^{45}$
}

${ }^{1}$ Center for Applied Geoscience, Universität Tübingen, Germany (*email: bhasker.rathi@uni-tuebingen.de)

${ }^{2}$ Flinders University, Adelaide, Australia

${ }^{3}$ Chinese Academy of Sciences, Guiyang, China

${ }^{4}$ CSIRO Land and Water, Floreat, Australia

${ }^{5}$ University of Western Australia, Crawley, Australia

Shallow Holocene aquifers underlying many highly populated areas of SE Asia are affected by high arsenic (As) concentrations. In contrast, deeper Pleistocene aquifers typically show lower As concentrations and are therefore increasingly targeted for drinking water production. However, it is feared that the hydraulic changes that are associated with excessive pumping could draw As contaminated groundwater into currently As free Pleistocene aquifers. Consequently, it is important to develop (i) a comprehensive understanding of the physical and geochemical processes and factors controlling As mobility in such settings and (ii) quantification tools that can support the necessary water management decisions.

In this study, we use reactive transport modelling to investigate the mobility of As in the redox transition zone (RTZ) that marks the Holocene/Pleistocene interface of an As polluted aquifer below Van Phuc, Vietnam, $\sim 10 \mathrm{~km}$ southwest of Hanoi. Constrained by field-measured hydrogeological, hydrochemical and mineralogical data we use our modelling framework to test a wide range of conceptual and numerical model variants to decipher the processes that govern the significant As retardation and attenuation that is observed within the RTZ. Speciically we attempt to identify the role of the various reductants contained in the Holocene groundwaters, including ferrous iron and ammonium, that migrate into the RTZ, where they drive iron mineral transformations that are associated with (i) the incorporation/co-precipitation of As into the mineral matrix and (ii) changes in the sorption capacity of the transforming iron mineral assemblage. As sorption is considered through a range of site-specific surface complexation models that were developed from batch sorption experiments with sediments that were sampled within different subzones of the RTZ.

[1] van Geen et al., Nature Communication. 2013

[2] Stopelli et al., Science of the Total Environment. 2020 